\title{
High Reliability Knowledge Networks: Responding to Animal Diseases in a Pastoral Area of Northern Kenya
}

\section{Alex Tasker \& lan Scoones}

To cite this article: Alex Tasker \& lan Scoones (2022): High Reliability Knowledge Networks: Responding to Animal Diseases in a Pastoral Area of Northern Kenya, The Journal of Development Studies, DOI: 10.1080/00220388.2021.2013469

To link to this article: https://doi.org/10.1080/00220388.2021.2013469

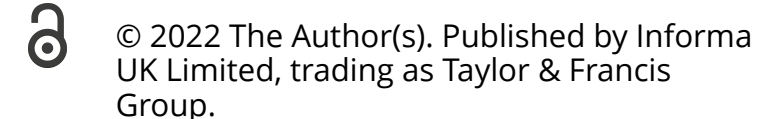
Group.

\section{+ View supplementary material $\widetilde{ }$}

曲 Published online: 10 Jan 2022.

\section{Submit your article to this journal $₫$}

Џلll Article views: 168

Q View related articles $₫$

View Crossmark data $\widetilde{\nearrow}$ 


\title{
High Reliability Knowledge Networks: Responding to Animal Diseases in a Pastoral Area of Northern Kenya
}

\author{
ALEX TASKER @** \& IAN SCOONES (1)** \\ *Anthropology Department, University College London, London, UK, **PASTRES Programme, Institute of Development \\ Studies, University of Sussex, Falmer, UK
}

(Original version submitted March 2021; final version accepted November 2021)

\begin{abstract}
How can reliability be generated and sustained in the face of uncertainty? This question is explored by examining knowledge networks among pastoralists and others in northern Kenya, emerging in response to a highly variable animal disease setting. Using quantitative and qualitative social network analysis, intersecting locallyembedded, development project and political networks are identified. Drawing on high-reliability theory, as applied to critical infrastructures, the paper explores the key characteristics of the knowledge networks in relation to systems, knowledges, relationships, technologies, professionals and politics. Reliability - the ability to provide stable services and respond variability in real-time - is shown to be related to the networked capacity to mobilise knowledge to confront uncertainty and avoid ignorance, with certain high-reliability professionals central. The locally-embedded network in particular has important characteristics of a high reliability knowledge network, but key brokers link to the development project and political network. Development challenges often require addressing uncertainty and even ignorance and lessons from high-reliability approaches can be crucial.
\end{abstract}

KEYWORDS: High reliability; social network analysis; uncertainty; pastoralism; Kenya

\section{Introduction}

How to generate reliable outcomes when things are so uncertain? This is a question asked by many, whether around natural disasters, climate change or disease pandemics. Pastoralists in remote regions face multiple uncertainties and sources of ignorance when confronting animal disease outbreaks. Focusing on pastoralists in northern Kenya, we demonstrate how these communities mobilise knowledge networks to generate reliability and stable outcomes.

In this paper, we use the idea of 'high reliability' more commonly applied in organisational theory to 'critical infrastructures', such as power stations, electricity grids and air traffic control (Roe \& Schulman, 2012; Schulman \& Roe, 2016). These settings seek to avoid catastrophic failures and manage high input variability. These systems demonstrate the continued presence of uncertainty where the probabilities of particular outcomes are unpredictable and unknown, and ignorance - where we don't know what we don't know (Scoones, 2019). This requires a set of processes and practices -

Correspondence Address: Alex Tasker, UCL Department of Anthropology, 14 Taviton Street, London WC1H 0BW, UK. Email: a.tasker@ucl.ac.uk

Supplementary Materials are available for this article which can be accessed via the online version of this journal available at https://doi.org/10.1080/00220388.2021.2013469. 
termed 'operational modalities' in critical infrastructure literature - to reduce high input variance, stabilising output variance to ensure reliable service delivery: the lights stay on, the nuclear power station does not melt down, and planes land safely.

Pastoralism can also be thought of as a 'critical infrastructure' (Roe, 2020). Through practices such as mobile herding, fodder provision, and disease control the highly variable, non-equilibrium environments that characterise pastoral areas are managed to ensure that a stable flow of livestock services and products continue to support livelihoods (Roe, Huntsinger, \& Labnow, 1998). High input variance includes environmental variables such as rain or snowfall, and so availability of grass and water, but also economic, social and other livelihood factors. Uncertainties dominate pastoralists' lives, and are seen by these communities not as hazards to be avoided, adapted to or coped with, but to be embraced and even lived off (Krätli \& Schareika, 2010).

Living with and from uncertainty requires mobilising different sources of knowledge, including knowledge about possible futures even if unpredictable. It also requires knowledge about immediate day-to-day and seasonal changes affecting capacities to manage livestock under uncertain conditions, whether the state of natural resources or the effects of insecurity and conflict in an area. This knowledge gathering and sense-making for action requires high reliability knowledge networks, rooted in relations among diverse people. In this article, we focus on how pastoralists mobilise knowledge networks to confront uncertainties around livestock disease.

We ask, to what extent do different networks generate reliability (low output variance in the face of high input variance) and what features of these networks enhance this? Focusing on one challenge and a limited set of networks allows us to probe the form and function of networks used by pastoralists in a particular setting. As we discuss at the end of the paper, animal disease challenges sit alongside many others; we acknowledge that the networks we explore here are a sub-set of a much wider array of networks and relations constructed to embrace the inevitable uncertainties and avoid the dangers of outright ignorance.

We argue that insights into the form and composition of pastoralist knowledge networks that generate reliability have wider implications for development. Standard development practices often ignore uncertainty, undermining capacities to respond to increasingly common highly turbulent, high-variance settings across a range of domains. We suggest a high reliability framing, and insights on knowledge networks are relevant to wider conversations around responding to a world dominated by uncertainties.

\subsection{High reliability and pastoralism}

Organisational and policy analysts working on high reliability management in critical infrastructures characterise high reliability behaviour as the creation of predictability from the unpredictable (Laporte \& Consolini, 1991; Rochlin, 1993, 1996). Suggested characteristics of high reliability organisations include systematic learning from experience, the ability to identify wider patterns and scenarios, and linking wider systems understanding with real-time practice (Roe et al., 1998). Organisations that are able to foster adaptive learning, reflective experimentation and situational awareness are more effective at managing turbulence, while effective organisational features include redundancy, modularity and flexible scenarios.

Central to the search for reliability are 'reliability professionals'. These are people, usually connected through informal networks, who enhance reliability and ensure the supply of stable services. Transforming high-input variance through a range of processes to low output variance requires a range of capabilities, strategies and options. One process is to scan the horizon for possible dangers by modelling possible scenarios and exploring diverse options through testing and focused experimentation. Another is to keep track of ground-level events as they unfold, creating localised scenarios about what might happen and thinking ahead to the next step. Crucially, high reliability professionals can track between these domains, continuously shifting the scope and focus, translating diverse sources of formal, experiential and tacit knowledge into action to ensure service supply. 
Relationships and networks are key. High reliability in an electricity supply system might involve those in the control room, along with IT specialists, equipment suppliers, business continuity consultants, regulators and others connected through formal and informal relationships built on trust, communication and learning. Whilst protocols, regulations and rules are necessary, the shared, real-time knowledge and learning occurring rapidly as situations unfold is often more necessary. These high reliability professionals are often not recognised or rewarded for these roles, yet they are vital for safe, reliable system functioning.

Studies of networks in high reliability management of critical infrastructures (e.g. Berthod, GrotheHammer, Müller-Seitz, Raab, \& Sydow, 2017) have rarely systematically analysed the knowledge dimensions of such relationships (although, see Baker, Day, \& Salas, 2006; Carroll \& Rudolph, 2006). While high reliability theory has been applied to pastoral settings (e.g. Roe, 2020; Roe et al., 1998), the nature of networks and the role of knowledge in generating reliability has not been explored.

Studies of pastoralism have long recognised the importance of variability in the management of livestock (Behnke, Scoones, \& Kerven, 1993; Krätli et al., 2016). These studies highlight the significance of sudden shocks and slower onset disasters resulting from droughts, conflicts or market volatility (Mcpeak, Little, \& Doss, 2012). The implications of these drivers for livelihood resilience and sustainability, social differentiation and inequalities have also been widely explored (e.g. Catley, Lind, \& Scoones, 2013; Lind, Sabates-Wheeler, Caravani, Kuol, \& Nightingale, 2020; Scoones et al., 2020). In this extensive literature, a detailed focus on knowledge mobilisation across networks to confront major challenges such as livestock disease are rarely addressed (although, see Homann, Rischkowsky, Steinbach, Kirk, \& Mathias, 2008).

Research on knowledge networks in development studies has historically focused on the macro-level, analysing networks among national and international organisations (Maxwell \& Stone, 2007). Studies of policy processes have explored how narratives - storylines about policy problems and solutions - are constructed and shared between actors within networks (Keeley \& Scoones, 2003), but such research does not typically delve into the details of knowledge exchanges, nor develop a quantitative analysis of such relationships. Studies of development practice frequently uses the metaphor of networks to explain how actors relate to each other and how particular brokers, intermediaries and gatekeepers operate, for example in the implementation processes of aid programmes (Lewis \& Mosse, 2006). Yet again, such approaches offer only broad, qualitative insights into such relationships and the actors involved. Researchers have however adapted quantitative social network analysis methodologies to more localised contexts to address a wide range of subjects (see, for example, Bouwer, Pasquini, \& Baudoin, 2021; Chaudhuri, Roy, Mcdonald, \& Emendack, 2021), including livestock disease in pastoral areas (Tasker, 2020). Network approaches provide powerful tools to examine the complexity of pastoral settings, but the intersecting and multi-layered nature of networks is often a barrier to this type of research. The analysis of multiplex networks - those with multiple relationships between the same actors - provides a more detailed and realistic picture of social realities (Hanneman \& Riddle, 2005), but require significant efforts on behalf of the researcher to identify and capture relationships.

In this study, we explore multiplex networks in a pastoral area, drawing on social network analysis but bringing this firmly into a development context. We aim to understand how knowledge is mobilised to address animal disease challenges in northern Kenya. In particular, we highlight the importance of overlapping networks - and key individuals within them - as the basis for generating high reliability.

\section{Study area and methods}

We explore these questions among the Gabra pastoralist community of North Horr, $200 \mathrm{~km}$ northwest of Marsabit town, the administrative capital of Marsabit County (Figure 1). This is an extremely dry region, with an average annual rainfall of $150 \mathrm{~mm}^{1}$ and pastoralism - extensive livestock keeping using a mix of camels, cattle, sheep and goats - is the dominant form of production accounting for 80 per cent of livelihoods in the County. 




Figure 1. Map of study site.

Animal health is a major impediment to pastoral production. Recent studies have identified Peste des Petit ruminants (PPR), contagious caprine pleuropneumonia (CCP), sheep- and goat pox, tickborne diseases, helminthosis and pneumonia as key diseases of smallstock (Abdilatif, Onono, \& Mutua, 2018), and trypanosomiasis, brucellosis, mastitis, diarrhoeas, worm infestations, camel pox and tuberculosis in camel populations (Lamuka, Njeruh, Gitao, \& Abey, 2017). In 2019, the Marsabit County census estimated the population at 459,785 people, ${ }^{2} 215,234$ camels 744,474 goats, 627,832 sheep, ${ }^{3}$ and in 2009, 28,162 cattle. ${ }^{4}$ Many Gabra pastoralists have diversified livelihood species and now mix sedentary and mobile livestock strategies (Watson et al., 2016) in combination with diversified livelihood activities including trading, waged employment, and farming (Little, Smith, Cellarius, Coppock, \& Barrett, 2001).

Pastoralists' deep knowledge of animal health and disease spans multiple generations, and is embedded in cultural relations and practices (Waller \& Homewood, 1997). Today such knowledges intersect with other sources of understanding and expertise, coming from state actors as well projects supported by non-governmental organisations (NGOs). In Marsabit, the droughts of the 1970s and 
1980s led to a marked increase in the number of relief and development agencies operating in pastoral areas of Kenya over the following decades (Fratkin \& Roth, 2005). A range of externallyfunded projects has provided access to alternative networks of animal health knowledge and resources, often in the absence of state-supported veterinary services, which were further reshaped by the contraction of state support due to structural adjustment economic reforms. As in other farming settings, herders had to respond to an evolving knowledge context by integrating different sources of knowledge, often creating hybrid forms, linking 'scientific' and 'indigenous' knowledges (Agrawal, 1995; Scoones \& Thompson, 1994). This resulted in the emergence of diverse hybrid knowledge networks, involving a number of brokers and knowledge intermediaries (see Mosse, 2001 for further discussion).

In this study we ask, how do such sources of knowledge intersect around responses to animal diseases and who are the key actors? We focus on animal health and disease for analytical tractability, but we could have examined livestock water provision, marketing, fodder management, herding labour, off-farm income earning, or any other aspect of pastoral systems and wider development. The study employed a mixed qualitative and quantitative comparative social network analysis (SNA) and used the framework proposed by Herz, Peters, and Truschkat (2014) for qualitative structural analysis (QSA). QSA approaches enable contextual understanding of knowledge exchanges through deeper evaluations of meaning and content than solely quantitative SNA approaches (Crossley, 2010). The quantitative assessment used as of betweenness and degree centralities as indices of actor position within the network. Degree centrality describes the number of connections between an individual and others, whereas betweenness measures the number of paths across the network through which each actor may exert influence. These metrics are helpful for identifying individuals who may occupy key positions within a network (Hage \& Harary, 1995)

The study was conducted during 2016 as part of a larger project examining knowledge networks (Tasker, 2018). Data collection was conducted through exploratory interviewing and mapping; initial findings were reviewed iteratively against existing research and local sense-checking with community collaborators and pastoralists. Snowball sampling was used to expand the studied networks, with network boundaries established through discussion with informants. Following open-ended questioning, semi-structured interviews were conducted to understand the type and direction of animal health knowledge exchanged, the nature of relationships and the context and motivation for exchanges. In total 113 relationships were recorded between 24 actors. These were 11 pastoralists, the Animal Health Assistant (AHA), an ex-Community Animal Health Worker (CAHW), The Community Disease Reporter (CDR), two agro-vet dealers, the 'chilres', the District Veterinary Officer (DVO), the County and Director of Veterinary Services (DVS), the North Horr Chief and Head of Police and VSF North Horr and Nairobi. Network plots in Excel and Gephi were presented to participants for feedback and verification interview transcripts were then analysed using thematic analysis, while the accuracy and relevance of the characterisations were further investigated through open-ended interviews with fourteen key informants from the overall network.

The overall network provides a topographical perspective on all connections, and within this subnetworks can be identified, each potentially reflecting shared social norms within the wider knowledge network (Millar \& Choi, 2009). After the overall network had been mapped, a modularity-class algorithm (Muff, Rao, \& Caflisch, 2005) was used to suggest sub-networks from their structural features, including proximity of members and number of inter- and intra-connected relationships, and these were reviewed against qualitative interview data. Three sub-networks were identified:

- Locally-embedded: local knowledge exchanges between pastoralists and service providers involving a number key brokers;

- Development project: exchanges around a development project, a NGO-led PDS (Participatory Disease Surveillance) programme ${ }^{5}$; and

- Political: A smaller network used to engage with external political systems. 
Limitations of the study should be highlighted. The networks identified included a majority of adult male herders, and gender- and age-specific networks were excluded, although ethnographic studies demonstrated their importance for some challenges (see below; Tasker, 2018). Within populations, relationships and networks exist in parallel across and within levels (Bolíbar, 2016), intersecting and reshaping one another in ways that may remain hidden or latent. Casual or contingent interactions may not be recalled in the analysis, but are nevertheless crucial. This study focused on livestock health networks only, but all these networks are necessarily situated within a much wider set of relationships, which can be drawn upon in addressing wider uncertainty and generating wider reliability.

\subsection{Livestock disease generates high input variance for the pastoral system}

Alongside other sources of variability, livestock diseases are an important source of uncertainty for pastoralists, with a number of different diseases having major impacts on livestock production (see table 1: 'Disease incidence in Marsabit district showing high input variability' in additional materials). Diseases are often seasonal, increasing in the rainy season for those transmitted through particular vectors or water. Some diseases are endemic and continuously present in the population, resulting in ongoing disease impacts, while others are epidemic outbreaks, sometimes only after long periods such as Rift Valley Fever, when heavy rainfall (associated with El Niño climate events) results in the emergence of dormant mosquitoes in low-lying areas and the transmission of the disease.

Different diseases have different effects: some result in chronic conditions resulting in higher morbidity and lower milk production and calving/kidding rates, while others can result in significant mortality, especially of vulnerable breeding and young stock. Differing patterns of livestock ownership result in different consequences of diseases; large animals and large herds may respond differently to those with few goats or sheep. Pastoralists therefore respond to high levels of disease variability, in a wide variety of ways.

Government veterinary services recognise the threat of livestock diseases on production, but struggle to address these challenges due to under-resourcing of state services and a lack of support for private alternatives (Leyland, Lotira, Abebe, Bekele, \& Catley, 2014). Gaps left by insufficient state and private sector veterinary coverage have driven searches for alternative animal health services and provision. NGO-supported community animal health workers (CAHWs) have been an important intervention, although non-accredited, local provision has been resisted by state veterinary services in Kenya (Catley et al., 2004; Sikana, Bazeley, Kariuki, \& Fre, 1992). However, pastoralists who engage with CAHWs can limit the impacts of disease and improve their production levels (Allport, Mosha, Bahari, Swai, \& Catley, 2005). Many pastoralists also engage with the 'Duka model', purchasing therapeutics through general stockists or informal channels (Mugunieri, Omiti, \& Irungu, 2002).

Alongside external animal health options, pastoralists make use of local, specialised knowledge networks. Detailed taxonomic classifications and nuanced veterinary knowledge are interwoven with other knowledge around rangelands, climate risks and markets (Liao, Ruelle, \& Kassam, 2016). Access to knowledge is highly differentiated - for example by age, gender or wealth - and individual herders must negotiate plural networks by drawing from a range of sources, access to which may depend upon their position and power.

In sum, disease incidence shows high levels of input variability, with potentially major impacts on morbidity and mortality of livestock. To respond, pastoralists must mobilise knowledge from different sources across different networks. Those most able to navigate these complex relationships can enhance reliability, defined as the continuous provision of critical services, and so reduce impacts on livestock and improve livelihoods. Pastoralists are capable of piloting a complex technical system - livestock - through periods of high variability and uncertainty using, as we shall see, a variety of networks. The next section explores the three contrasting knowledge networks we identified in this study. 


\section{Results}

\subsection{Three knowledge networks: what generates and sustains reliability?}

Our first step was to map all 113 knowledge exchanges across the overall network of 24 actors based on the coded interview data. As discussed earlier, three sub-networks were identified within the overall network (Figure 2).

The next sections explore the three sub-networks. In each section, we present the quantitative analysis and network centrality measures before moving to in-depth qualitative analysis. A complete table of network calculations is available in additional materials under 'table 2: network measures'.

3.1.1. Network 1: the locally-embedded network. Figure 3 maps the 'locally-embedded network' based on a quantitative analysis of knowledge exchanges. In this graph, and others that follow, node size is proportional to the betweenness centrality, while degree centrality is represented by the number of connections. This network contained 81 relationships between 19 actors and is characterised by the use of local livestock health and disease knowledge. In terms of measures of centrality, the core network actors were the CAHW (degree $(d)=22$, betweenness $(b)=97.2$ ), agro-

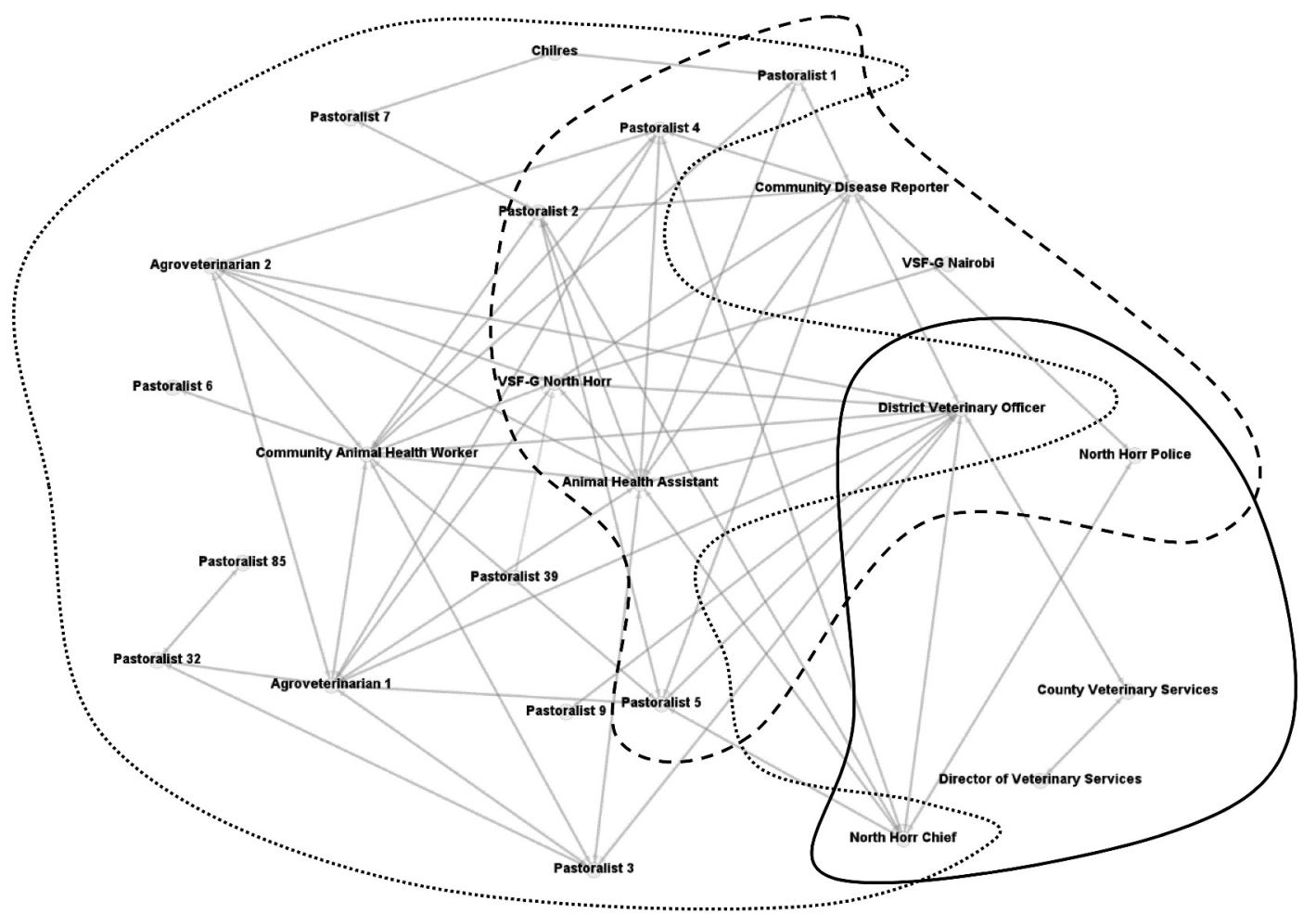

Locally-

embedded sub-

network

\section{Development}

Sub-network
Political sub-

network

Figure 2. Overall network, with three sub-networks. 


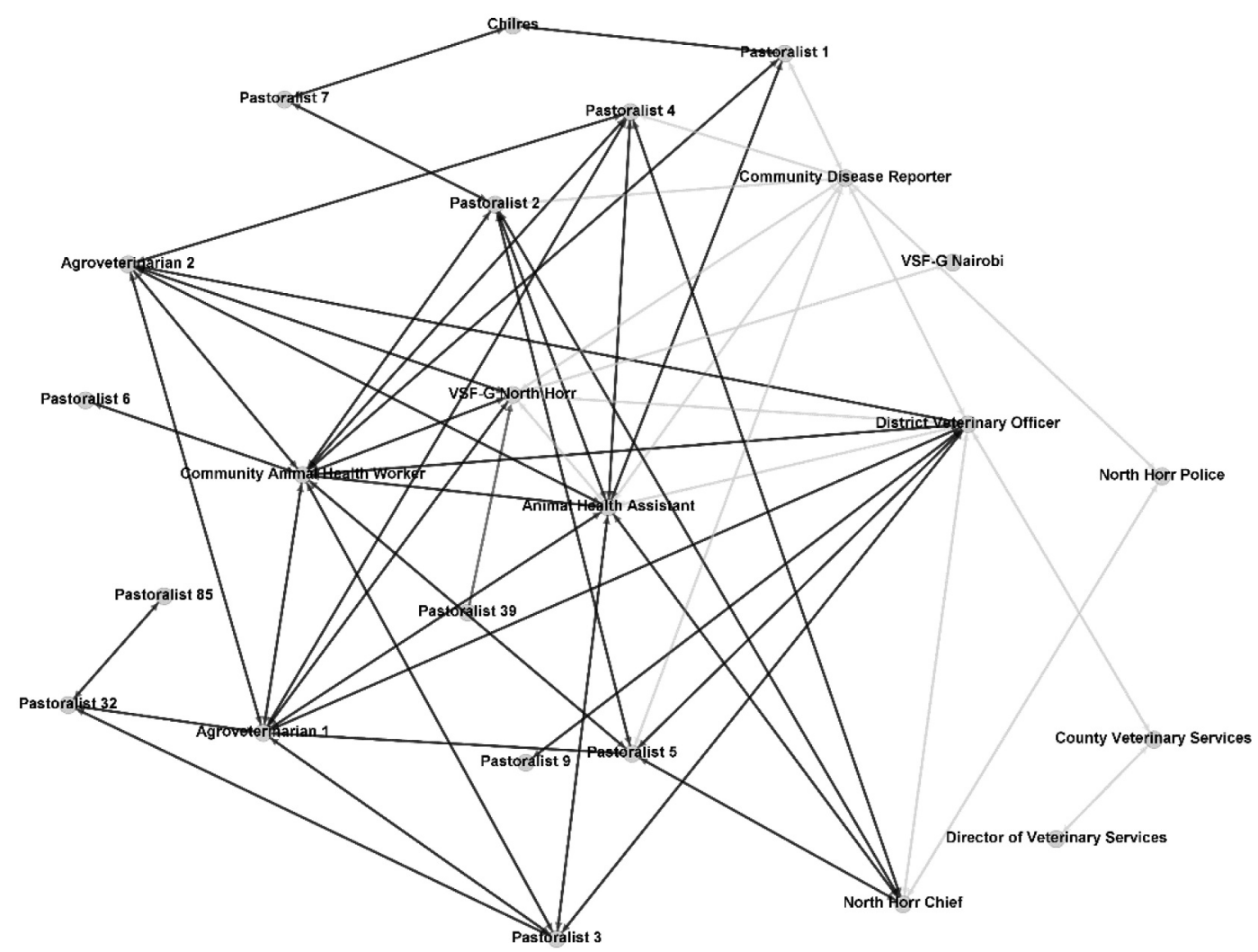

Figure 3. Locally-embedded network.

veterinarian $^{6} 1(d=18, b=53.8)$ and $2(d=12, b=7)$ and the AHA $(d=16, b=34.7)$. Full network values are given in the supplemental materials.

Knowledge exchanges, according to informants, follow a real-time, open format, emphasising group engagement and sharing. One pastoralist suggested:

You see a herder doing something new, or hear daimtu (knowledge exchange) that a disease may be treated differently, and you will think of this. When you are with your friends you will talk of the new thing, and they will also have heard or you will tell them. You may send word to friends who know, or telephone a different manyatta (settlement), or ask an elder who is knowledgeable of these things. Then you decide if it is right for you, your household. And you may try it, but always you will talk of how it is, how it was. (Pastoralist 2)

Pastoralists describe how their own knowledge exchanges differed at collective and individual levels:

Many things change, but this is our culture, and we may do what we need and want. If someone comes to our community and he is doing something different, we will come and see. We will ask. We will talk to others who know about his things and see if it is for us. If it is good or bad, the Gabra will talk. If it is good, herders may choose it; even if it is bad some may choose it still but do it differently, in his way. Like medicines for sick camels - you will talk to those who know, and choose to use them if you can find them and can pay. (Pastoralist 85)

Such processes of 'co-construction', where epistemic and normative orders emerge together, highlight how knowledge and action are intertwined in this network, with pastoralists seeking 
and giving help on very practical issues. The type of challenges identified in knowledge exchanges varied widely from sources of feed and fodder, to market prices, to disease outbreaks and the loss of animals through accident or illness, to upcoming NGO vaccination schemes. Exchanges around animal health therefore did not focus only on the supply of drugs or vaccines, but included discussions around local treatments, the movement of livestock, the deployment of herding labour to improve nutrition and so health, the specialist care for sick animals or the splitting of herds to reduce vulnerabilities of particular animals to disease effects through quarantining practices. These exchanges were often multi-layered and cross-referenced. By way of example, when discussing the health of camels for marriage dowry, herders would also consider emerging 'mystery' respiratory diseases, alongside anticipated sale prices in the United Arab Emirates for the next Hajj.

Particular individuals are especially central to this network. Their positions enable them to influence the flows and content of knowledge exchange within and outside of the network. The role of the chilres within this network is an example. Often mistranslated as a 'livestock expert' or 'traditional healer', the role of the chilres is better characterised as a broker and gatekeeper to different sources of knowledge on animal health and disease within what we are calling here the locally-embedded network. Pastoralists describe the chilres as a collator of knowledge on treatment approaches using cultural channels and local technologies to advise, or to direct individuals to alternative sources of knowledge or resources. For instance, in exchanges recorded during the network mapping, the chilres discussed treatment approaches used by non-Gabra herders such as the Boran, Turkana and Samburu for Rinderpest and Foot-and-Mouth disease. The format of these conversations was central: discussions were broad and discursive, often involving the telling of stories and relaying of anecdotes. The information sharing acted to inform and contextualise herder decisions rather than aim for any kind of consensus. This was a stark difference to the advice from the veterinary department or NGO actors where information was framed in terms of singular, technical recommendations and presented in a one-way exchange, rather than emerging through a more open discussion. When asked about his choice of livestock advice, a young herder contrasted the chilres and NGO employees:

I know him (the chilres) well, he is a good man, a clever man. He and I talk about many things, he knows about animals very much; but also about families, women and children. And schooling. You may ask him many things that he can tell you ...... When you go (the NGO), you cannot say my animal has this or this, you must ask them only to help you. Then they will tell you 'I have this or this', you can ask them for their knowledge, but they follow the programme that they have. If they are digging wells, then you have water. If they are vaccinating, then that is what you will have. (Pastoralist 7)

The chilres maintained his role as a cultural knowledge broker through experience and embedded networks within local society. A key relationship was with the Animal Health Assistant (AHA) - also a local Gabra herder who was employed by the state as a subordinate of the (non-Gabra) DVO and CVO.

The AHA was a central contact that enabled the chilres and, by extension, the wider Gabra community to gain access to networks of veterinary science and state livestock health resources. Thanks to his involvement in the locally-embedded network, the AHA was adept at bridging cultural and hierarchical barriers. He combined his positions as a livestock-owning male Gabra with being technologically literate and occupying a government position, and so having accredited legitimacy. This permitted privileged entry into other knowledge domains and, like the chilres, he acted as an important broker and intermediary:

You cannot sit with (the NGO) people, you cannot talk with them as we (the Gabra) talk. He (the AHA) sits every night, he herds his animals, he is at weddings and he will be with us when it 
rains and when it does not. But he is clever and he has a good job, a job that means he can talk to NGO, to government. He can make them hear us and can tell us what they say, and what they do not say. What is good for him is good for us. (Pastoralist 4)

The bridging ability of the AHA was also understood by actors in the government veterinary service. When interviewed, the DVO stressed the hierarchical difference between him and the AHA, but acknowledged the increased access the AHA's embedded position granted - particularly around disease surveillance:

Of course he (the AHA) knows much, but he has not had the training (that I have) ..... he (the AHA) knows the community well, they are his tribe, his family. When there are problems that are difficult for me to solve, then he will often know what the community are doing to address them. When an outbreak happens, he will know before I am told. (DVO)

The AHA's position also enabled localised experimentation and adaptation. Under the PDS scheme, the DVO was required to provide confirmatory diagnosis of livestock disease; there were, however, no resources for treatment following diagnoses. Responding to the shortfall, the AHA engaged local treatment providers to accompany the DVO on field visits, facilitated by NGO vehicles. The navigation of intersections between government, NGO and locally-embedded networks exemplifies many of the features of high reliability systems of service provision, enabled by the AHA's multiple identities.

Most pastoralists, however, lacked the contacts to engage an NGO as a first step. Instead, many herders would approach the ex-Community Animal Health Worker (CAHW) who, despite having been formally removed from state services, retained a wide range of contacts. Describing the CAHW's role, one herder noted:

The CAHW knows the animals and the government well, he has many friends and people who he knows and work with. He is a good man for North Horr as they (the government) will know us and our problems. He may not have the same vehicle as before, but he is still a powerful person for us and for them (government). (Pastoralist 4)

This characterisation of CAHWs as 'good' and 'powerful' highlights the wide recognition of the value of external expertise, but also the need to have local contacts embedded in wider networks to secure and provide access. The bridging of networks by the CAHW (together with the chilres and AHA) also serves to reinforce their position across multiple networks, both local and beyond, allowing for a diversity of sources of knowledge to be drawn up in local responses to animal health challenges. In many cases, the capacities of bridging individuals are enhanced through linguistic expertise. The way in which the CAHW was able to navigate skilfully between Oromo, Kiswahili and English echoes observations by Mahmoud (2008) on the importance of multi-lingual dilaal, or 'gobetweens', for traders in nearby Moyale.

Today, all these exchanges are facilitated by the use of mobile phones. Despite limited network coverage in the district (Parlasca, Mußhoff, \& Qaim, 2020), connectivity continues to increase substantially in the last decade, shifting the nature and speed of knowledge exchange. With Whatsapp, the possibility of discussions across groups increases, and exchanges can be less unidirectional and more in the form of wide exchange and discussion. Even so, the key roles of the core actors in the network remains, as their advice and suggestions are deferred to. A herder explained:

He (the agro-veterinarian) is a good man, we talk often. He knows many things about new drugs and treatments, and he helps very much. Now we are talking on WhatsApp when there are 
bigger things ..... in this group he knows many things, he can help very much. If you need to know how to get blood tests, he can talk to friends and give you help. (Pastoralist 32)

While the AHA and CAHW showed high levels of betweenness and degree centrality in the quantitative mapping, this was not the case for the chilres. However, despite there being fewer recorded direct connections in knowledge exchanges, his role - especially together with the AHA - is clearly crucial in this network. As the CAHW mentioned:

The Gabra are always learning, and always changing. This is important, very important. We learn through talking - inside and outside (the community). Men like the chilres they know so many things about my family and our lives, but also the Somali and Borana. They talk more and listen more and hear more and can tell what they know. A man he will say 'my uncle has a sick goat' The chilres knew a Somali who had sick goats like this and he showed how he must treat them'. This is very different to me (the CAHW). I would tell them the drugs, I would say the ways in which they must treat the sickness. But the chilres, he will be able to find those who have seen this before - maybe even me! (CAHW)

These multiple network relationships and positionalities, and the ability to move between different knowledge domains, illustrates the fundamental importance of the chilres, AHA and CAHW in this locally-embedded network. As those able to scan wider sources of knowledge - from other pastoral areas or from formal veterinary science - and connect these to the day-to-day realities of pastoral production systems through processes of learning, local experimentation and social and technical innovation, they are quintessential high reliability professionals. They are able to bridge and connect networks and respond to challenges as they arise in real-time and communicating widely across the community. By being reliable in real-time, right now when it matters, this locally-embedded network is able to maintain longer-term relationships, building ongoing, two-way exchanges that develop relationships over time. Embedding these exchanges of knowledges in vernacular forms - storytelling, using local terminologies, linking to cultural metaphors and well-known sayings, songs and poems (Tablino, 1999) - also enables exchange to occur easily and rapidly, including sharing across and between ethnicities and cultural groups (Schlee, 1989). That the exchange is two-way means that learning occurs, and responsiveness to rapidly unfolding situations is possible.

Despite the effectiveness of this network in generating reliability in the face of highly variable animal disease contexts, reliability is generated selectively. Unequal power structures within pastoral societies mean that, despite the claims, not everyone can benefit from the locally-embedded high reliability network. Connections are built on Gabra solidarities, and so those from other ethnic groups are excluded. Clan and kin loyalties affect some relationships, although the key high reliability professionals have a wide reach. Those able to make additional, direct connections with veterinary officials and NGOs tend to be the more powerful and wealthy male pastoralists, who are able to travel to town, having mobile phone credit to get in touch with people or having transport to bring an officer to a herd or flock.

This network is therefore formed around a set of (usually) older, male pastoralists and the issues addressed very much focus on their concerns. These include the health of larger more mobile stock under the management of male pastoralists, rather than the management of smallstock at homesteads, and issues around milking and the care of young animals, which tends to be the domain of women (Mcpeak \& Doss, 2006). While there are undoubtedly other networks associated with these challenges and involving mostly women, the way such networks connect and their power and influence within local society shows how knowledge networks and the construction of reliability is inevitably a complex process, affected by power relations and patterns of differentiation locally.

3.1.2. Network 2: the development project network. The 'development project network' contained 25 relationships between 11 actors, and was focused on a joint NGO-Government livestock health 
reporting project, the Participatory Disease Surveillance (PDS) programme (Figure 4). In terms of measures of centrality, the core network actors were the CDR $(d=16, b=65)$, the VSF lead in North Horr $(d=8, b=17)$, and two representatives of state veterinary services, the DVO $(d=7, b=9)$ and AHA $(d=6, b=0)$.

In North Horr, the training for the CDRs focused on reporting 'notifiable diseases and those of economic importance' to District and County Veterinary Officers (Kimondiu, Duehnen, \& Buono, 2016). The programme was specifically designed to strengthen links between livestock keepers and government service providers through collaborative investigations and treatment planning.

The PDS programme was generally well received by herders who made use of it and linked with the project actors, notably the CDRs. In contrast to the locally-embedded network, exchanges were more formalised and transactional. A prominent herder commented, 'In the past VSF have provided many good things; they have medicines and can help us sell animals' (Pastoralist 5). When pressed, he elaborated that his involvement in the project was less driven by a need for immediate treatments and more about establishing and maintaining an ongoing relationship and access to future projects. When asked about this, an NGO staff member suggested the benefits were 'an improved awareness by livestock keepers on disease control and more effective conventional veterinary practices'.

The project is thus founded within an hierarchical relationship of knowledges, and less based on a process of co-construction and dialogue as in the locally-embedded network. It assumes that the accredited, veterinary knowledge is the ultimate arbiter and can filter out what is effective and ineffective local knowledge. As we have discussed, pastoralists do make use of externally-derived scientific knowledge and value this alongside their own understandings, but their engagement with this network is selective and largely instrumental.

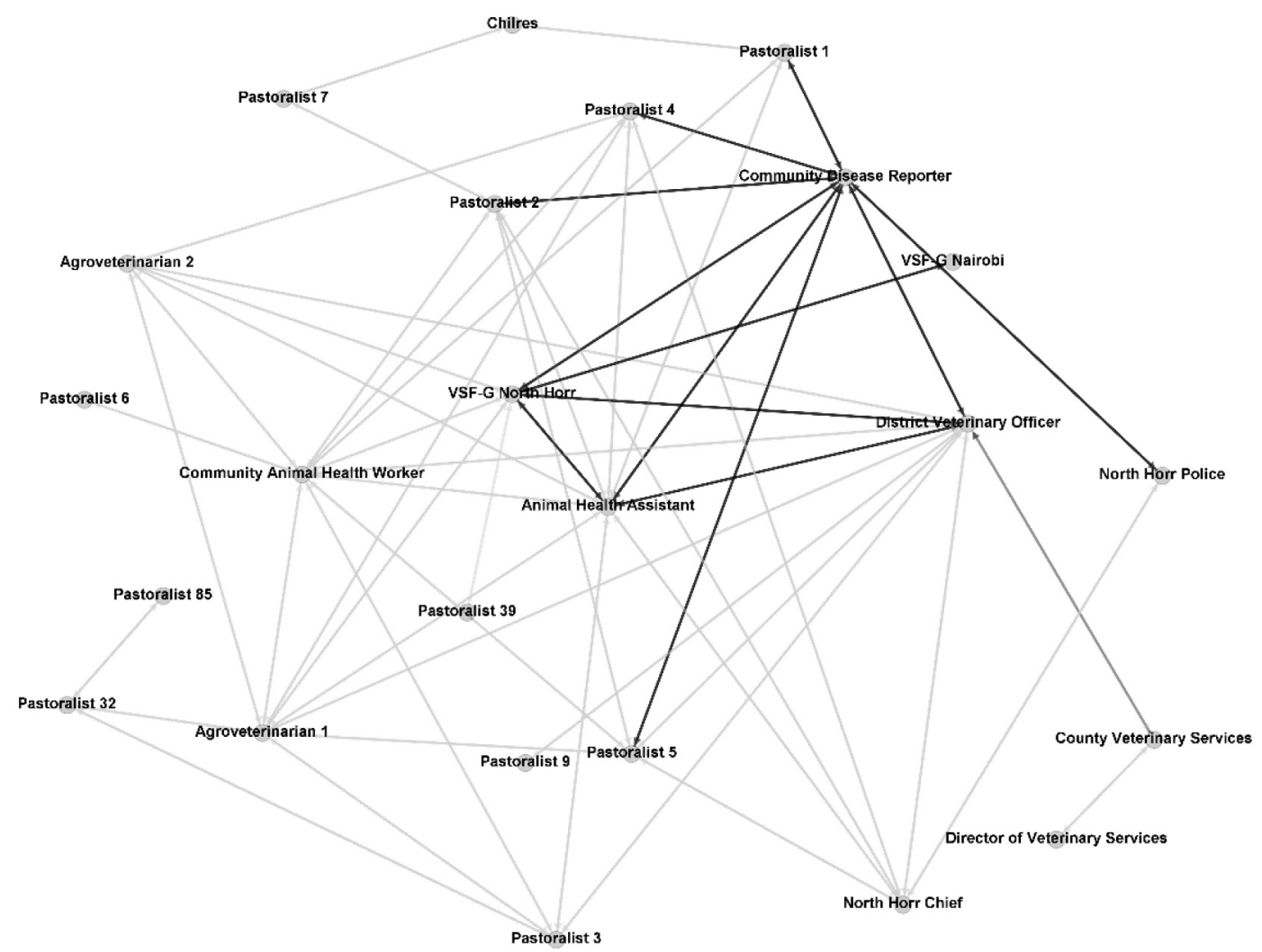

Figure 4. Development project network. 
That said, the community-based recording of disease incidence has been useful in particular instances (Catley, 2006). While disease identification and reporting helped mobilise external support from state veterinary officers, the reporting was upwards through an accredited, formal body with responsibility assigned by the state. The relationships are derived from state-based veterinary practice, which allows only formally-qualified veterinarians to be involved in disease response and treatment. This means that the development project network is narrower, reliant on a single individual (the CDR), connected to the AHA, the DVO and the project (VSF), and involving a structured gatekeeping relationship, rather than the facilitator, broker roles seen in the locally-embedded network. The DVO suggested that, 'he (the CDR) is my ears in the community, he can see what is going on. He is trained to report the diseases, the outbreaks, and we (veterinary service providers) will work out what should be done'. Because of the regulations and protocols there is less flexibility and greater reliance on a single professional within the network - the CDR - and a hierarchical relationship with a circumscribed and filtered set of knowledges. The CDR reflected on his close alignment with the DVO: 'the (PDS) project is very good, as it uses the knowledge of the people. We (the CDR and DVO) are able to tell the government what we need doing, how are animals are sick'.

In terms of high reliability management theory, this network shows fewer of the key features of scanning across knowledge domains, learning and deliberation, local experimentation and innovation and flexibility in response compared to the locally-embedded network. However, due to the connections across networks facilitated by the CAHW/AHA, the reliability features of the locally-embedded network can feed into this network, even though this is not acknowledged or even recognised by the project and the state veterinary service.

As in the locally-embedded network, there are exclusions; not only of particular types of local knowledge deemed unacceptable by the accredited veterinarians, but also of certain actors. The networks mapped here again involved only men, and those supplying information to the CDR inevitably focused on the disease challenges that their domain of pastoral management faced. Those with time and connections - including those investing in these relationships in the hope of future project support - again tended to be men who were richer, large herd owners focused on the management of large-stock, notably camels.

3.1.3. Network 3: the political network. The 'political network' has only five actors and seven connections, and is linked to the locally-embedded and development project networks through the Chief, the Head of Police and the DVO. The network also includes actors not in the other two networks including the Country Veterinary Officer (CVS) and County Director of Veterinary Services. Although only five actors were mentioned as being directly exchanged with by pastoralists around animal health issues (and so mapped here), all are conduits to wider networks, including to local M.P.s, as well as other government actors, business people and diaspora connections. In terms of measures of centrality, the core network actors were the North Horr Chief $(d=4, b=4)$, DVO $(d=3, b=4)$, and CVS $(d=3, b=3)$.

While not drawn upon frequently and not seen as central to day-to-day management of uncertainties, pastoralists pointed to the importance of gaining access to wider sources of support via key individuals through the political network. For example, the local M.P., who has been important in directing resources to the area, was connected to WhatsApp groups that included the Chief and/or the DVO. This forum in turn afforded members access to an elite Gabra diaspora spanning from the USA to Asia. The DVO suggested that the group was 'supporting the Gabra who wish to make more, go further, so they can continue helping our community'.

Connections to the political network helped in pushing government officials, including the veterinary service, to respond. These wider connections are important for generating reliability. Mobilising investments and generating political and funding support to the area helps more widely to reduce vulnerabilities, enhancing the capacity to respond to uncertainties. Such support may come 
in the form of investment (in infrastructure for example), in direct cash support to those struggling (through social protection programmes) and through expertise (from specialist research). Political connections are important too when disasters strike. For example, when many smallstock owned by local herders were injured in a truck accident, herders contacted the Chief, who was charged with finding a political contact to apply pressure to the Marsabit police department so that compensation would be provided.

As Figure 5 shows, the political network overlaps with the two other networks and members of the locally-embedded network were very aware of the political network. However, brokers, such as the Chief, were required to gain access to political connections. Exchanges with the political network involved individual approaches by particular pastoralists on certain issues, as well as more collective lobbying around local challenges. Here particular pastoral elders with standing in the community become important, as they carry with them credibility amongst locals and the ability to reach out to politicians and more senior government officials. In this way, the day-today functioning of the larger locally-embedded network is linked to the narrower political network. Clearly, such relations are not available to everyone, and it is far from guaranteed that male elders will automatically represent everyone.

Some of these relationships could be cast negatively in terms of clientelism or patronage relations. However, networked relationships are crucial for boosting reliability in a highly networked social and political system affecting everyone. While the political network per se is less about response to immediate disease uncertainties, it is more about supporting the wider community to reduce vulnerabilities through the channelling of support. In this sense, pastoralists argue, such connections, based largely on elite links and kin/clan relations between particular individuals, contribute to wider system reliability through the boosting of capacities to respond.

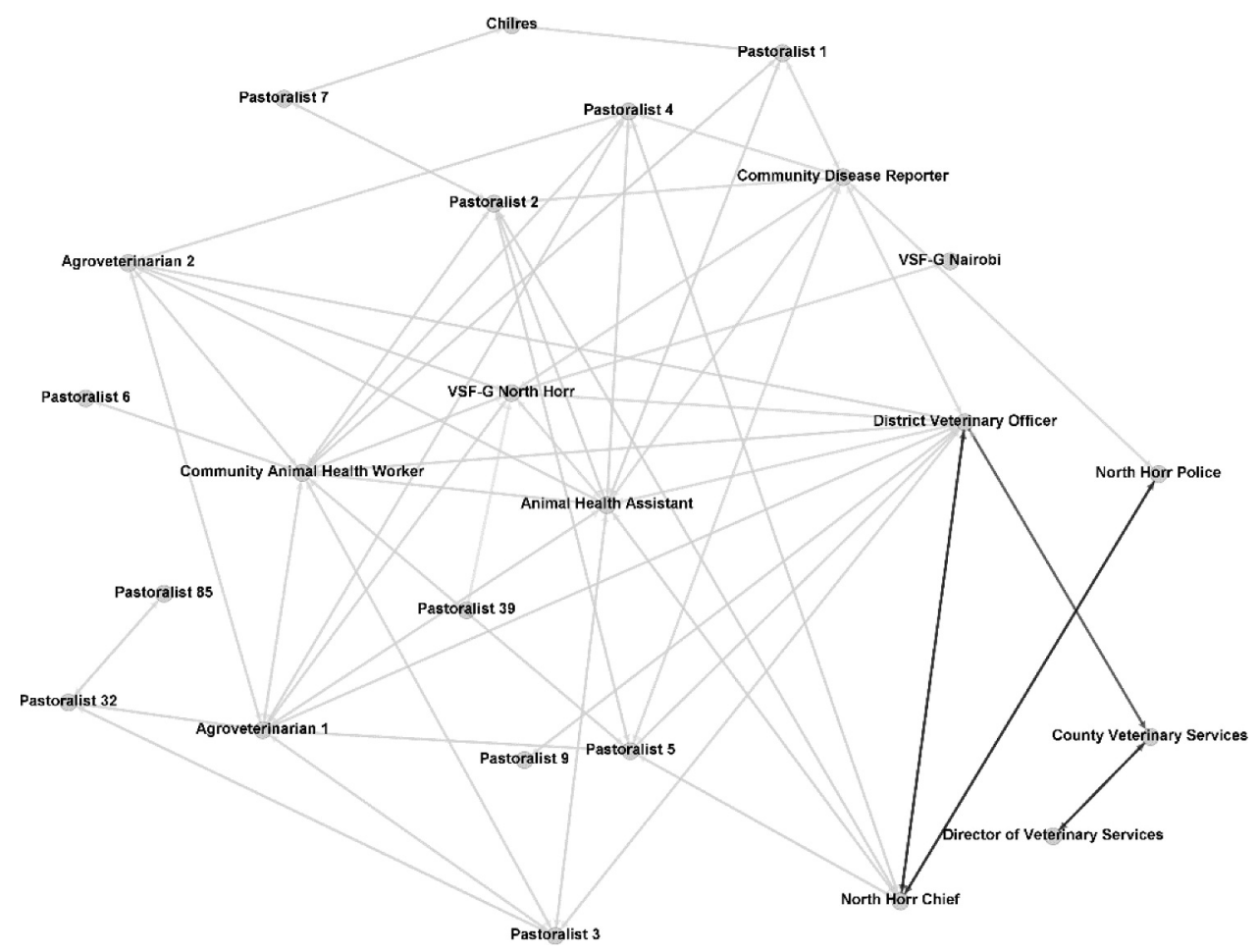

Figure 5. The political network. 


\section{Discussion}

\subsection{Generating reliability: key features of knowledge networks}

Looking across the three networks, we can identify six key features of knowledge networks that contribute (or not) to the generation of reliability in a highly uncertain animal health/disease setting. Through these framings, processes and practices, high input variance is translated into lower output variance in the provision of services (in this case through livestock), and so into more resilient livelihoods. These six features, we argue, are relevant to other contexts where mobilisation of knowledge across networks is essential for confronting uncertainty and ignorance. Given this is a common, although often under-played, feature of most development settings, we argue that these features may have wider relevance.

4.1.1. Systems. The three networks emerge from differing definitions of the systems to be managed, with implication for how service reliability is generated in the face of uncertainties, as well as surprises that may emerge suddenly. In the locally-embedded network, a wide bounding of the system is demonstrated, with the objective being the protecting of livelihoods from disease shocks. To that end, the system incorporates not only livestock and pathogens but also wider cultural, social and political features, and relationships that include links to state services and other ethnic groups.

The development project network by contrast is more narrowly focused. Its objective is to improve surveillance and disease reporting of a list of known animal diseases through a well-defined system, involving a specified array of actors through a participatory disease reporting system. The objective here is to identify and control disease through the intervention of veterinary expertise, focused on known risks where estimated outcome probabilities can be assessed through information gathering and analysis. The political network is even more targeted when it comes to specific issues related to livestock. Network actors are differentially engaged, depending on the issue, and exchanges are focused on a narrow objective around mobilising knowledge and, especially, resources.

4.1.2. Knowledges. As noted already, there are major contrasts in the sources of knowledge that are made use of in the different networks. In the locally-embedded network, experiential, tacit knowledge is combined through cultural frames with externally-derived knowledges in different ways, coconstructing hybrid forms of real-time knowledge. A sense of seeking out different experiences and expertise through searching, discussing and evaluating is particularly evident. Knowledge is not seen as fixed or divisible from action, but is emergent, and linked to action. The focus is on real-time responses and rapid action in the face of unfolding, uncertain conditions; what we have been calling high-input variance.

While the development project network explicitly makes use of multiple sources of knowledge, these are viewed hierarchically with scientific knowledge from credentialed professionals having the role of filtering and selecting useful knowledge derived from local settings. The focus is on identifying particular disease risks through a classic form of risk management, where estimated probabilities are assessed through a surveillance and reporting system. Knowledge is less situated locally and linked to real-time action, as knowledge must be collected, reported, analysed and acted upon, largely sequentially and governed by a limited number of defined actors within specified, hierarchical relationships. There is less of a sense of co-construction, but more one of extraction for later instrumental use. A similarly hierarchical relationship is evident in the political network, where knowledge flows uni-directionally from those in power and with resources to pastoralists, via different brokers and intermediaries.

4.1.3. Relationships. Within and between networks, relationships are the defining element when it comes to meeting service reliability mandates. Our quantitative analysis highlighted measures of centrality (direct and betweenness) in each network, and different patterns were observed, with the 
locally-embedded network having a greater number of actors and relationships, and a larger group of core actors at its centre. These actors can be seen as high reliability professionals, in that they act as brokers, connectors, facilitators and networkers, and are able to link knowledges on the wider system (scanning horizons, thinking about next steps ahead) with local, day-to-day contexts. Together, the chilres, AHA and CAHW show a variety of relational characteristics vital to assuring service reliability through the network. They are rooted in cultivated, reciprocal relationships and cultural forms that are widely trusted, and are the result of continuous social investment over time.

The development project network also depends on key relationships, but these are hierarchically structured within a project frame. As a project, with funding constraints and institutional commitments, it is a time-constrained network less embedded in long-term social relationships, and dependent on external resources. Although there are is overlap in membership with the locally-embedded network, the social and political nature of relationships is quite different. However, it is the less visible, unacknowledged connections between the two networks that add to the overall system reliability. Here the importance of key reliability professionals - the AHA and CAHW - are underscored. The political network has again a hierarchical set of relationships, but links between those with particular types of knowledge can only be made through access to certain brokers, who are engaged on a case-by-case basis.

4.1.4. Technologies. Technologies are important in both networks and phones and Whatsapp connections take centre-stage. As one pastoralist noted, 'Phone credit is better medicine for the camel than blood tests'. Phones are used in different ways, resulting in different technological 'affordances' within the networks. In the locally-embedded network, it is two-way learning and exchange that is essential and allows for effective, rapid responses. Dialogue and deliberation on emerging challenges is facilitated by WhatsApp groups, where collective knowledge can be applied. Informal connections to other networks - notably the political network - help mobilise resources from outside the area, as well as the ability to draw on wider sources of expertise such as through searching the Internet, though limited coverage remains a barrier to wider use

In the locally-embedded network, the end point may not only be the delivery of a particular drug or vaccine, but a wider set of management responses - such as movement, fodder supply, herd splitting and so on. By contrast, in the development project network, mobile phones are used for transfer of information within a reporting system. The availability of phones - and the wider infrastructure that makes this possible - ensures disease reporting is rapid and effective. Accredited expertise is in turn offered to pastoralists essentially in a uni-directional way, with a set of defined animal health messaging and disease treatments, focusing on drugs and vaccines.

While the development project network's veterinary response is much appreciated and widely used, it focuses on generalised risk-based knowledge. A risk is defined through surveillance and disease reporting and a response results, usually focused around particular disease treatments. By contrast, engagement with the political network is much more case-specific, whereby phone connections are key to linking to those in distant and more powerful places. The flow of information is again uni-directional and situated: specific requests or petitions are made, and specific responses may or may not follow. In other words, these two networks are less attuned to addressing unfolding and intersecting uncertainties and wider ignorance around really complete surprises, and so less effective at generating real-time reliability for a variety of key services related to animal health and diseases.

4.1.5. Professionals. Within the three networks there are strategic individuals, usually with high degrees of centrality in network measures. They are the individuals who are central to generating reliability. They connect, bridge and provide knowledge and can act both to scan wider sources of knowledge and understand the local context, tracking between the two. As people who have lots of insight - tacit and explicit - and who have experimented with locally-realistic, alternative solutions over time, they are innovators who provide the basis for others to follow. In the locallyembedded network we identified the triad of the chilres, the AHA and CAHW as the high 
reliability professionals, emerging from their relationships in the network. The AHA and CAHW provide a link to the development project network, and so connections across networks, again building the capacity for response. In addition to their relational positions in the network, such individuals have personal characteristics that make them successful in these roles. They have charisma, a good reputation and are seen as local and so highly trusted. All these qualities add to their professional expertise in managing uncertainty and responding to surprises. By contrast, the other two networks are not built around such reliability professionals, although the AHA and the CAHW are present in the development project network. Instead, those with high centrality (the CDR and the DVO, for example) act less to mediate knowledge across the network, both scanning horizons and responding to local change, but are more gatekeepers between different parts of a network, providing information in a hierarchically-organised relationship.

4.1.6. Politics. As we saw with the political network, connections to politicians and elite actors within the state helps to galvanise support for the community. While this is less important in the day-to-day response to uncertainty, it is nevertheless vital to generate support for the community in the form of investment in infrastructure, for example, as well as the response to particular disasters. In mobilising wider action across the political network, individuals are again important and the status of 'elder' in the pastoral setting is especially significant in the leverage of political connections and commitment.

In sum, these six features define how pastoralists mobilise knowledge to confront uncertainties around animal health in this context. A broad definition of the system, the deployment of plural knowledges, the investment in diverse relationships, the use of technologies to facilitate knowledge exchange and the key role of particular individuals, with certain professional capacities, in brokering and facilitating across networks, are all important. And overall, there is a clear recognition that politics matter in mediating networked relations, both opening up opportunities and closing them down. At one level, such findings seem obvious, but when we contemplate how development policies are framed and projects are designedhere around animal health in Kenya, but much more broadly too - then we can see how important such features can be in rethinking development policy and practice more widely.

\section{Conclusion}

What does the high reliability approach add to our understandings of how pastoralists confront uncertainties, and especially those generated by animal diseases? After all, we have known for a long time that pastoralist networks and relationships matter in these production systems, and that these are based in kinship, cultural and broader political factors and contexts (Scoones et al., 2020). Such networks and relationships become all the more important as conditions of uncertainty increase. So what is new here, and if new, why do these insights matter for development, now and in the future? Necessarily speculative, four sets of insights follow:

\subsection{Networks are key to differentiating complex systems}

Pastoral systems are complex and the high reliability approach highlights the importance of positions and relationships in different networks that ensure the continuous provision of key services, especially under uncertain, turbulent conditions. The three networks discussed here highlight different, but complementary, roles; although of course there is no presupposition that networks across different contexts will be the same.

\subsection{High reliability professionals are at the centre of these networks}

In the high reliability approach, prices, technologies, livestock and other network components are mediated through the actions of real-time reliability professionals and their networked relationships in this case centred on responding to livestock disease, the chilres, AHA and CAHW. If we had 
focused how reliability is generated in other areas of pastoral production, other networks of reliability professional could be identified. For instance, 'scouts' - often on motorbikes and using mobile phones - have an important role in assessing grazing and water availability, including the impact of insecurity, before livestock are moved. While such professionals may hold often exclusive and highly gendered positions in local society, the relationships that they are the centre of are key to generating reliability, and everyone benefits from the provision of stable livestock services and outputs.

\subsection{Network knowledge is unique in the complex system}

The knowledge of networked professionals for ensuring real-time service provision under difficult conditions consists of skills, expertise and situational awareness rooted in their networks and their relationships. To label this knowledge as 'indigenous ecological knowledge', 'traditional local knowledge' or 'ethno-veterinary knowledge' does not go far enough to capture the networked professionalism spanning the three networks identified; a feature present, we suspect, in other pastoral systems and development contexts as well.

\subsection{High reliability networks have a major, but under-acknowledged, role in and for politics}

Political relationships, both formal and informal, are central to pastoral settings, affecting the power relations central to network functioning. That said, the high reliability approach demonstrates a complexity that is more granular. For example, one reason why the political network here was smaller and more case-specific might be because the other two networks provide the infrastructure that is needed so that the political network can be drawn upon as and when required.

Reliability therefore can be seen as the networked capacity to mobilise knowledge to confront uncertainty and avoid ignorance. Our analysis suggests that the approach pursued in this article connecting high reliability management approaches with social network analysis - can have wider relevance for development.

First, our findings suggest a new way of thinking that puts uncertainty - and in turn reliability - at the centre of analysis and action for development. Second, there are methodological implications that highlight the need to go beyond snap-shot survey assessments to look at relationships within networks in order to explore complex development settings. Third, there is a need to recognise the roles of particular individuals - here identified as 'reliability professionals' - within development practice, and the importance of supporting their roles and capacities in addressing inevitable uncertainties and sources of ignorance. Fourth, networks - formal and informal, temporary and more permanent - always overlap and intersect, and effective action emerges from this interaction. This has implications for project design, for example, seeing 'the project' not as a stand-alone network, but inevitably integrated into local, more embedded networks of knowledge and practice, as in the case here. And finally, our findings confirm that both the constitution of networks and their functioning is highly contingent on politics, including in how relationships are constructed, how individual high reliability professionals operate and how knowledge and in turn action to respond is mobilised under conditions of uncertainty.

Given the significance of uncertainty and ignorance in development challenges - in everything from responses to pandemic diseases to infrastructure development to humanitarian and disaster responses to addressing climate change - greater attention to knowledge networks as routes to assuring high reliability in development could pay real dividends.

\section{Notes}

1. https://reliefweb.int/sites/reliefweb.int/files/resources/Marsabit_Climate_Risk_Profile_Final.pdf.

2. https://www.knbs.or.ke/?wpdmpro=2019-kenya-population-and-housing-census-volume-i-population-by-county-and-subcounty.

3. https://knoema.com/KELP2020/livestock-population-by-type-and-district-kenya-2019. 
4. 2009 represents the most recent whole-county cattle data available.

5. The PDS project was implemented by Veterinaires Sans Frontieres Germany (VSF-G), using a form of 'participatory epidemiology' led by a Community Disease Reporter (CDR).

6. The agro-veterinarian is a locally-recognised role that includes the provision of livestock advice, and the sale of medicines and feedstuffs.

\section{Acknowledgements}

AT undertook the field research and quantitative network analysis with funding from the Uk Economic and Social Research Council (ES/J500173/1). The data that supports the findings is available on request from the author; this data is not publicly available due to participant statements of consent for sharing. Fieldwork was supported by Vétérinaires sans Frontìeres Germany (VSFG) and research assistants, Abdoub Guyyoo, Yarra Adano, Solomon Oba and Martha Galgalo. The network analysis and writing of this paper undertaken both by AT and IS, and was stimulated by interactions with Emery Roe over many years. The writing and publication of the article was supported by the ESRC STEPS Centre (steps-centre.org, Grant: ES/R000158/1) and the European Research Council Advanced Grant to the PASTRES programme (pastres.org, Grant: 740342).

\section{Funding}

This work was supported by the Economic and Social Research Council [ES/J500173/1,ES/R000158/ 1]; European Research Council Advanced Grant [740342].

\section{Disclosure statement}

No potential conflict of interest was reported by the author(s).

\section{ORCID}

Alex Tasker (1) http://orcid.org/0000-0003-3836-6078

Ian Scoones (i) http://orcid.org/0000-0001-8547-4464

\section{References}

Abdilatif, M. H., Onono, J. O., \& Mutua, F. K. (2018). Analysis of pastoralists' perception on challenges and opportunities for sheep and goat production in Northern Kenya. Tropical Animal Health and Production, 50(7), 1701-1710.

Agrawal, A. (1995). Dismantling the divide between indigenous and scientific knowledge. Development and Change, 26(3), $413-439$.

Allport, R., Mosha, R., Bahari, M., Swai, E., \& Catley, A. (2005). The use of community-based animal health workers to strengthen disease surveillance systems in Tanzania. Revue Scientifique et Technique: Office International des Epizooties, 24(3), 921.

Baker, D. P., Day, R., \& Salas, E. (2006). Teamwork as an essential component of high-reliability organizations. Health Services Research, 41(4p2), 1576-1598.

Behnke, R. H., Scoones, I., \& Kerven, C. (1993). Range ecology at disequilibrium. London, UK: Overseas Development Institute.

Berthod, O., Grothe-Hammer, M., Müller-Seitz, G., Raab, J., \& Sydow, J. (2017). From high-reliability organizations to high-reliability networks: The dynamics of network governance in the face of emergency. Journal of Public Administration Research and Theory, 27(2), 352-371.

Bolíbar, M. (2016). Macro, meso, micro: Broadening the 'social' of social network analysis with a mixed methods approach. Quality \& Quantity, 50(5), 2217-2236.

Bouwer, R., Pasquini, L., \& Baudoin, M.-A. (2021). Breaking down the silos: Building resilience through cohesive and collaborative social networks. Environmental Development, 39, 100646. 
Carroll, J., \& Rudolph, J. (2006). Design of high reliability organizations in health care. BMJ Quality \& Safety, 15(suppl 1), i4i9.

Catley, A. (2006). Use of participatory epidemiology to compare the clinical veterinary knowledge of pastoralists and veterinarians in East Africa. Tropical Animal Health and Production, 38(3), 171-184.

Catley, A., Leyland, T., Mariner, J., Akabwai, D., Admassu, B., Asfaw, W., ... Hassan, H. S. (2004). Para-veterinary professionals and the development of quality, self-sustaining community-based services. Revue Scientifique Et Technique: Office International Des Epizooties, 23(1), 225-252.

Catley, A., Lind, J., \& Scoones, I. (2013). Pastoralism and development in Africa: Dynamic change at the margins. Abingdon, UK: Routledge.

Chaudhuri, S., Roy, M., Mcdonald, L. M., \& Emendack, Y. (2021). Reflections on farmers' social networks: A means for sustainable agricultural development? Environment, Development and Sustainability, 23(3), 2973-3008.

Crossley, N. (2010). Towards relational sociology. Abingdon, UK: Routledge.

Fratkin, E., \& Roth, E. A. (2005). As pastoralists settle: Social, health, and economic consequences of the pastoral sedentarization in Marsabit District, Kenya. New York: Springer.

Hage, P., \& Harary, F. (1995). Eccentricity and centrality in networks. Social Networks, 17(1), 57-63.

Hanneman, R. A., \& Riddle, M. (2005). Introduction to social network methods. Riverside, CA: University of California Riverside.

Herz, A., Peters, L., \& Truschkat, I. (2014). How to do qualitative structural analysis: The qualitative interpretation of network maps and narrative interviews. Forum Qualitative Sozialforschung/Forum: Qualitative Social Research, 16(1), Art. 9, http://nbn-resolving.de/urn:nbn:de:0114-fqs150190. FQS http://www.qualitative-research.net/

Homann, S., Rischkowsky, B., Steinbach, J., Kirk, M., \& Mathias, E. (2008). Towards endogenous livestock development: Borana pastoralists' responses to environmental and institutional changes. Human Ecology, 36(4), 503.

Keeley, J., \& Scoones, I. (2003). Understanding environmental policy processes: Cases from Africa. London: Routledge.

Kimondiu, S. M., Duehnen, W., \& Buono, N. (2016). Participatory epidemiology: Approaches, methods, experiences. Nairobi, Kenya: V.S.F. Germany.

Krätli, S., Kaufmann, B., Roba, H., Hiernaux, P., Li, W., Easdale, M. H., \& Huelsebusch, C. (2016). A house full of trap doors. Identifying barriers to resilient drylands in the toolbox of pastoral development. EGU General Assembly Conference Abstracts (pp. 7762). Vienna, Austria (EGU General Assembly 2017, 17-22 April 2016).

Krätli, S., \& Schareika, N. (2010). Living off uncertainty: The intelligent animal production of dryland pastoralists. The European Journal of Development Research, 22(5), 605-622.

Lamuka, P. O., Njeruh, F. M., Gitao, G. C., \& Abey, K. A. (2017). Camel health management and pastoralists' knowledge and information on zoonoses and food safety risks in Isiolo County, Kenya. Pastoralism, 7(1), 20.

Laporte, T. R., \& Consolini, P. M. (1991). Working in practice but not in theory: Theoretical challenges of" high-reliability organizations". Journal of Public Administration Research and Theory: J-PART, 1(1), 19-48.

Lewis, D., \& Mosse, D. (2006). Development brokers and translators: The ethnography of aid and agencies. W. Hartford, CT: Kumarian Press.

Leyland, T., Lotira, R., Abebe, D., Bekele, G., \& Catley, A. (2014). Community-based animal health workers in the horn of Africa an evaluation for the office of foreign disaster assistance. Great Holland: Feinstein International Center, Tufts University Africa Regional Office, Addis Ababa and Vetwork UK.

Liao, C., Ruelle, M. L., \& Kassam, K. A. S. (2016). Indigenous ecological knowledge as the basis for adaptive environmental management: Evidence from pastoralist communities in the Horn of Africa. Journal of Environmental Management, 182, $70-79$.

Lind, J., Sabates-Wheeler, R., Caravani, M., Kuol, L. B. D., \& Nightingale, D. M. (2020). Newly evolving pastoral and post-pastoral rangelands of Eastern Africa. Pastoralism, 10(1), 1-14.

Little, P. D., Smith, K., Cellarius, B. A., Coppock, D. L., \& Barrett, C. (2001). Avoiding disaster: Diversification and risk management among East African herders. Development and Change, 32(3), 401-433.

Mahmoud, H. A. (2008). Risky trade, resilient traders: Trust and livestock marketing in northern Kenya. Africa, 78(4), $561-581$.

Maxwell, S., \& Stone, D. L. (2007). Global knowledge networks and international development. Abingdon, UK: Routledge.

Mcpeak, J. G., \& Doss, C. R. (2006). Are household production decisions cooperative? Evidence on pastoral migration and milk sales from northern Kenya. American Journal of Agricultural Economics, 88(3), 525-541.

Mcpeak, J., Little, P., \& Doss, C. (2012). A Risky Region. In J. Mcpeak, P. D. Little, \& C. R. Doss (Eds.), Risk and social change in an African rural economy: Livelihoods in pastoral communities (pp. 54-79). London, UK: Routledge.

Millar, C. C., \& Choi, C. J. (2009). Networks, social norms and knowledge sub-networks. Journal of Business Ethics, 90(4), $565-574$.

Mosse, D. (2001). 'People's knowledge', participation and patronage: Operations and representations in rural development. In B. Cooke, and U. Kothari (Eds.), Participation: The New Tyranny (pp. 16-35). London, UK: Zed Books.

Muff, S., Rao, F., \& Caflisch, A. (2005). Local modularity measure for network clusterizations. Physical Review E, $72(5)$. doi:10.1103/PhysRevE.72.056107

Mugunieri, L. G., Omiti, J. M., \& Irungu, P. (2002). Animal health service delivery systems in Kenya's marginal areas under market liberalization: A case for community-based animal health workers (Report 3). Washington, DC: International Food Policy Research Institute. 
Parlasca, M. C., Mußhoff, O., \& Qaim, M. (2020). Can mobile phones improve nutrition among pastoral communities? Panel data evidence from Northern Kenya. Agricultural Economics, 51(3), 475-488.

Rochlin, G. I. (1996). Reliable organizations: Present research and future directions. Journal of Contingencies and Crisis Management, 4(2), 55-59.

Rochlin, G. I. (1993). Defining "high reliability” organizations in practice: A taxonomic prologue. In K. H. Roberts (Ed.), New challenges to understanding organizations (pp. 256). New York, NY: Macmillan Publishing Company.

Roe, E. (2020). A new policy narrative for pastoralism? Pastoralists as reliability professionals and pastoralist systems as infrastructure (STEPS Working Paper). 113.

Roe, E., Huntsinger, L., \& Labnow, K. (1998). High-reliability pastoralism versus risk-averse pastoralism. The Journal of Environment \& Development, 7(4), 387-421.

Roe, E., \& Schulman, P. R. (2012). Toward a comparative framework for measuring resilience in critical infrastructure systems. Journal of Comparative Policy Analysis: Research and Practice, 14(2), 114-125.

Schlee, G. (1989). Identities on the move: Clanship and pastoralism in Northern Kenya. Manchester, UK: Manchester University Press.

Schulman, P., \& Roe, E. (2016). Reliability and risk: The challenge of managing interconnected infrastructures. Stanford, CA: Stanford University Press.

Scoones, I. (2019). What is Uncertainty and Why Does it Matter?, STEPS Working Paper 105, Brighton: STEPS Centre

Scoones, I., Lind, J., Maru, N., Nori, M., Pappagallo, L., Shariff, T., ... Tsering, P. (2020). Pastoralism and development: Fifty years of dynamic change. IDS Bulletin, 51(1A), 1-20.

Scoones, I., \& Thompson, J. (1994). Beyond farmer first. Rugby, UK: Intermediate Technology Publications.

Sikana, P., Bazeley, P., Kariuki, D., \& Fre, Z. (1992). The Kenya livestock and pastoral programme: Some observations and reccomendations. Rugby, UK: Intermediate Technology Publications.

Tablino, P. (1999). The Gabra: Camel nomads of Northern Kenya. Nairobi, Kenya: Paulines Publications Africa.

Tasker, A. (2018). Processes of hybrid knowledge creation in pastoralist development (Doctoral thesis). University of Sussex.

Tasker, A. (2020). Exploring power and participation through informal livestock knowledge networks. Preventive Veterinary Medicine, 181, 105058.

Waller, R., \& Homewood, K. (1997). Elders and experts: Contesting veterinary knowledge in a pastoral community. In A. A. Cunningham \& B. Andrews (Eds.), Western medicine as contested knowledge (pp. 69-94). Manchester, UK: Manchester University Press.

Watson, E. E., Kochore, H. H., \& Dabasso, B. H. (2016). Camels and climate resilience: Adaptation in northern Kenya. Human Ecology, 44(6), 701-713. 